\title{
Ameliorative and Preventive Effects of Metformin, Nigella sativa, Punica granatum and Zingiber officinale on Bone Damage and Infections Caused by Diabetes mellitus in Animal Model
}

\author{
Nora Abdulaziz Aljalaud \\ Biology Department, College of Science, Imam Abdulrahman Bin Faisal University, Dammam - 31411, Saudi Arabia.
}

\begin{abstract}
Diabetes mellitus has emerged as a pandemic affecting both the genders and all the age groups. This metabolic disorder is classically notorious to cause retinopathy, neuropathy, micro and macro vascular complications including brain damage, cardiac disorders and nephropathy and renders patients to develop various kinds of infections Ginger, Nigella sativa and Punica granatum are strong antioxidants and possess antimicrobial activity. While the Metformin is known to reduce the insulin resistance. In present study we examined the influence of Ginger, Nigella sativa, Punica granatum and Metformin on the prevention and treatment of bone damage and infections due to Diabetes mellitus in STZ-induced diabetes in male Wistar albino rats. 40 rats were used in the study, and it was observed that all the studied substances prevented infections and bone damage at the same time, significant increase was found in the bone volume, strength, density, and length in comparison to diabetic rats.
\end{abstract}

Keywords: Diabetes mellitus, Infection, Animal model, animicrobial activity.

\footnotetext{
*Correspondence: naljalaud@iau.edu.sa; +966133337282

(Received: 20 January 2019; accepted: 02 March 2019)

Citation: Nora Abdulaziz Aljalaud, Ameliorative and Preventive Effects of Metformin, Nigella sativa, Punica granatum and Zingiber officinale on Bone Damage And Infections Caused by Diabetes mellitus in Animal Model, J Pure Appl Microbiol., 2019; 13(1):465473 doi: 10.22207/JPAM.13.1.52

(C) The Author(s) 2019. Open Access. This article is distributed under the terms of the Creative Commons Attribution 4.0 International License which permits unrestricted use, sharing, distribution, and reproduction in any medium, provided you give appropriate credit to the original author(s) and the source, provide a link to the Creative Commons license, and indicate if changes were made.
} 


\section{INTRODUCTION}

Diabetes mellitus is a chronic metabolic condition that leads to a high plasma glucose levels ${ }^{1,2,3}$. Diabetes mellitus primarily results from, defect in feed mechanism leading to disordered homeostasis, defect in the secretion of insulin or defective insulin resistance adjuvant to inadequate insulin secretion.

Type 2 diabetes mellitus is characterized by the inability of efficient insulin use, referred to as insulin resistance joined with an inability to secrete a ample amount of insulin to outcome the insulin resistance. T2DM usually leads to severe complications which involve the heart, blood vessels, eyes, kidneys, and nerves. It has also been observed that diabetes badly affects bone health.

$\mathrm{DM}$ is known to enhance and lengthen inflammation, that may add to enhanced bone breakdown. Diabetes mellitus escalates osteoclast synthesis in a number of conditions including periodontal disease, fracture healing and osteoporosis ${ }^{4,5,6}$.

It was revealed that intraperitoneal administration of Nigella sativa (thymoquinone) significantly decreases hyperglycemia in STZ induced DM in the rats ${ }^{7}$.

It is widely known that, Metformin is the first-line pharmacotherapeutic agent for the pharmacological treatment of T2DM. It turns down the blood glucose levels, and that is due to decreasing hepatic gluconeogenesis and elevation of glucose intake by the skeletal muscle ${ }^{8,9}$.

It has been observed that metformin, an oral hypoglycemic agent and also an insulin sensitizer, ameliorates bone breakdown and rate of turnover. When treated with Metformin, T2 Diabetics have reduced risks of bone fracture ${ }^{10}$. The bone formation effects of metformin have been observed in cellular and experimental animals, mainly metformin augments bone formation and suppresses adipocyte differentiation in cultured rat model, marrow mesenchymal stem cells, most likely due to inhibition of PPAR $\gamma$, which is a nuclear receptor responsible for regulation off at and glucose metabolism ${ }^{11}$, metformin also stimulates trabecular bone synthesis by activation of AMPK signaling in osteoblastic cells, a leading intracellular pathway which senses energy deficiency ${ }^{12}$.

On the contrary, metformin straightly suppresses bilateral ovariectomy-induced bone damage in rats ${ }^{13}$ and osteoclastogenesis ${ }^{14}$, that is also demonstrated by a substantial decrease of serum bone resorption marker $(-12.7 \%)$ in male diabetic patients using metformin ${ }^{15}$.

The effects of Thymoquinone on bone degradation, bone formation and bone healing as well as abnormalities related to bone has been reported in some fields. Thymoquinone (actie ingredient of Nigella sativa) may be beneficial in osteogenesis ${ }^{16}$. Analysis of the physiological responses of Thymoquinone (Nigella sativa) in the femoral defect animal model has shown continuous delivery of the drug and was successful in bone healing. It has been confirmed that the alveolar bone loss due to periodontitis reduces by gastric Thymoquinone when administered to rats. Thymoquinone (Nigella sativa) also reduces the number of osteoclasts and increases osteoblastic activity ${ }^{17}$.

Moreover, it has been found that systemic use of Thymoquinone (TQ) in rats resulted in significant acceleration of bone development. Systemic administration of $10 \mathrm{mg} / \mathrm{kg}$ of TQ can boost bone synthesis and may prove to be good in preventing the relapse after the rapid maxillary expansion (RME) procedure. In consideration of potent antioxidant properties, Nigella Sativa (TQ) may prove to have a critical role in speedup bone formation. Nigella sativa (TQ) reduces the ROS production and the consequent pro-inflammatory cytokines IL- 1 and -6 and TNF-, cytokines that can add to the differentiation of osteoclast precursors and osteoclast activity leading to bone resorption ${ }^{18}$.

Infectious diseases are routinely found in patients who develops T2DM and are serious, causing significant increase in the morbidity and mortality. The higher prevalence of infections in diabetic patients is due to the increased blood glucose environment which favors immune disorder (e.g., destruction of neutrophil function, suppression of the antioxidant system, and humoral immunity), micro- and macro-angiopathies, neuropathy, reduction in the antimicrobial activity of urine, gastrointestinal and urinary disability, and frequent medical interventions in the patients. The infections affect all the organs and systems of a body. After all, majority of researchers conclude that there is clinical testimony pointing out to the greater incidence of infectious diseases among 
individuals suffering from Diabetes mellitus ${ }^{19,20,21}$.

Gingerols are one of the main ginger active components that cause inhibition of production of inflammation-causing prostaglandins ${ }^{22}$. Possible effects of ginger which cause inhibition of hepatic phosphorylase is to decrease hepatic glycogenolysis and to increase activity of the enzymes that lead to progression of glycogenesis. Other probable effect of ginger may be suppression of the activity of hepatic glucose6-phosphatase enzyme, that causes reduction in blood glucose levels ${ }^{23}$.

It has been found that ginger potential anti hyperglycemic that may also be due to its effects on serotonin receptors, in addition to increase in the pancreatic production of insulin from beta islets or release of bound insulin ${ }^{24}$.

Punica granatum L. (pomegranate) is a seasonal plant, which is widely spread as a source of conventional medicine ${ }^{25,26}$. The pomegranate fruit has medicinal effects like antiinflammatory and antibacterial activities. The seed oil of pomegranate is rich in phytoestrogenic compounds and the fruit also contains in phenolic compounds with substantial anti-oxidant activity ${ }^{27}$.

Oxidative stress has an important role in the occurrence of complications in diabetes, especially type II $\mathrm{DM}^{28}$.

It has been found in several studies that Type II DM is linked with oxidative stress, which causes increased generation of free radicals, like superoxide radical, hydrogen peroxide, and hydroxyl radical, or reduced antioxidant immune mechanism ${ }^{29,30}$. The role of oxidative stress in the pathogenesis of DM is not only due to free radical production, but also due to non-enzymatic protein glycation, damaged antioxidant enzyme system and formation of peroxides ${ }^{31}$.

Free radicals are divided into reactive oxygen species (ROS), reactive Nitrogen species $(\mathrm{RNS})^{32}$, and reactive chlorine species (RCS) ${ }^{33}$.

In some conditions, oxygen may be flowing in the cells when it generates reactive species which lead to necrosis and sequentially the cell end. RNS and RCS also cause oxidation by the proliferation of some tool which intrude with the normal physiological homeostasis in the cell ${ }^{34}$.

\section{MATERIAL AND METHODS}

The present research was performed under Research units of College of Science, Imam Abdulrahman Bin Faisal University, Dammam, Saudi Arabia and Laboratory conditions at the department of Clinical Pharmacy, Faculty of Pharmacy, Northern Border University.

\section{Acquirement of plant material}

Ginger (Zingiber officinale), Seeds of Nigella sativa and Pomegranate (Punica granatum) were acquired from the regional market and the necessary preparations were done according to the research methodology.

Animals

Fourty adult Wistar albino male rats, of 8 weeks old and weighing $250 \pm 10 \mathrm{~g}$, were attained from the animal house of Faculty of Pharmacy, Northern Border University. Male rats were accommodated in temperature controlled rooms $\left(25^{\circ} \mathrm{C}\right)$ with continuous moisture (40-70\%) and $12 \mathrm{~h} / 12 \mathrm{~h}$ light/ dark cycle before their use in experimental protocols.

All animals were looked upon according to the Principles of Laboratory Animal Care. The experimental protocol approval was got, according to the guide for the care and use of laboratory animals prepared by Deanship of Scientific Research, NBU.

All the Rats were nourished with standard diet and water. The daily input of animal water was checked at least once a week before the start of treatments in order to calculate the amount of water required per experimental animal.

\section{Induction of Diabetes with STZ}

The Type II DM was produced in the animals by a single intra peritoneal injection of streptozotocin (STZ, Sigma-Aldrich, St.Louis, MO, USA) in $0.1 \mathrm{M}$ citrate buffer ( $\mathrm{pH} 4.0$ ) at a dose of 55 $\mathrm{mg} / \mathrm{kg}$ body weight (Mahesh and Menon, 2004). Blood glucose levels and variance in body weight were checked regularly.

Ten groups of the Wistar male rats were made, each group having 4 animals, as follows:

Group 1: Control rats were given only $5 c c$ Normal saline $(0.9 \% \mathrm{NaCl})$.

Group2: Control rats were given ginger $(100 \mathrm{mg} / \mathrm{kg} / \mathrm{rat})$ daily. 
Group 3: Control rats were given Nigella Sativa (80 mg/kg).

Group4: were given Metformin150 mg/

$\mathrm{kg} /$ day.

Group 5: were given Punica $400 \mathrm{mg} / \mathrm{kg} /$ day.

Group 6: Diabetic control (55 mg/kg, single intra peritoneal injection of STZ).

Group 7: Diabetic group ( $55 \mathrm{mg} / \mathrm{kg}$, single intra peritoneal injection of STZ) will receive 100 $\mathrm{mg} / \mathrm{kg} /$ day ginger.

Group 8: Diabetic group $(55 \mathrm{mg} / \mathrm{kg}$, single intra peritoneal injection of STZ) Nigella Sativa 80 $\mathrm{mg} / \mathrm{kg} /$ day.

Group 9: Diabetic group ( $55 \mathrm{mg} / \mathrm{kg}$, single intra peritoneal injection of STZ) will receive Punica $400 \mathrm{mg} / \mathrm{kg} /$ day.

Group 10: Diabetic group (55 mg/kg, single intra peritoneal injection of STZ) will receive Metformin $150 \mathrm{mg} / \mathrm{kg} /$ day.

$48 \mathrm{hrs}$ after the induction of experimental diabetes mellitus, the experimental protocol was started.

Surgical procedure

At the end of $6^{\text {th }}$ week (end of the treatment period, $24 \mathrm{hrs}$. after the last administration) the rats were sacrificed, after intraperitoneal administration of sodium pentobarbital solution (40 mg/ $\mathrm{kg}$ )as an anesthetic, and the long bones of limbs were taken. Immediately, from the control and experimental groups.

The weight of the bones for each group member was recorded. The animals were sacrificed by deep ether anesthesia. Disarticulation of fore and hind limbs from the axial skeleton was done with removal of soft tissue and fixation in $10 \%$ buffered formalin.

Microbiological examination of bone

After sacrifice, and removal of skin from long bones (Tibia), careful examination/inspection was done for any evidence of infection. The swabs

Table 1. Comparison of the Bone Parameters in different studied groups at different days.

\begin{tabular}{|c|c|c|c|c|c|}
\hline Groups & $\begin{array}{l}\text { Bone } \\
\text { length } \\
(\mathrm{mm})\end{array}$ & $\begin{array}{l}\text { Bone } \\
\text { thickness } \\
(\mathrm{mm})\end{array}$ & $\begin{array}{l}\text { Bone } \\
\text { weight } \\
\text { (g) }\end{array}$ & $\begin{array}{l}\text { Bone } \\
\text { volume } \\
\text { (ml) }\end{array}$ & $\begin{array}{l}\text { Bone } \\
\text { density } \\
(\mathrm{g} / \mathrm{ml})\end{array}$ \\
\hline $\begin{array}{l}\text { G6 (STZ } \\
\text { Diabetic control) }\end{array}$ & $41.77 \pm 2.16$ & $3.09 \pm 0.26$ & $1.07 \pm 0.10$ & $0.95 \pm 0.10$ & $1.00 \pm 0.00$ \\
\hline $\begin{array}{l}\text { G7 (STZ + } \\
\text { Zing off } 100 \text { mg } \\
\text { in Diabetic rats) }\end{array}$ & $44.70 \pm 2.64$ & $3.41 \pm 0.13$ & $0.98 \pm 0.22$ & $1.00 \pm 0.00$ & 0.920 .20 \\
\hline Significance & $1 P=0.031$ & $1 \mathrm{P}=0.027$ & $1 \mathrm{P}=0.331$ & $1 \mathrm{P}=0.415$ & $1 \mathrm{P}=0.319$ \\
\hline $\begin{array}{l}\text { G8 (STZ + } \\
\text { Nigella (80mg) } \\
\text { in Diabetic rats) }\end{array}$ & $44.50 \pm 1.41$ & $3.45 \pm 0.36$ & $1.13 \pm 0.18$ & $1.08 \pm 0.10$ & $1.07 \pm 0.09$ \\
\hline Significance & $\begin{array}{l}1 \mathrm{P}=0.043 \\
2 \mathrm{P}=0.880\end{array}$ & $\begin{array}{l}1 \mathrm{P}=0.014 \\
2 \mathrm{P}=0.780\end{array}$ & $\begin{array}{l}1 \mathrm{P}=0.458 \\
2 \mathrm{P}=0.093\end{array}$ & $\begin{array}{l}1 \mathrm{P}=0.037 \\
2 \mathrm{P}=0.180\end{array}$ & $\begin{array}{l}1 \mathrm{P}=0.380 \\
2 \mathrm{P}=0.068\end{array}$ \\
\hline $\begin{array}{l}\text { G9 (STZ + } \\
\text { Punica (400 mg) } \\
\text { in Diabetic rats) }\end{array}$ & $41.89 \pm 2.97$ & $4.18 \pm 0.22$ & $1.11 \pm 0.09$ & $1.05 \pm 0.08$ & $1.05 \pm 0.07$ \\
\hline Significance & $\begin{array}{l}1 \mathrm{P}=0.922 \\
2 \mathrm{P}=0.039 \\
3 \mathrm{P}=0.053\end{array}$ & $\begin{array}{l}1 P=0.001 \\
2 P=0.001 \\
3 P=0.001\end{array}$ & $\begin{array}{l}1 P=0.597 \\
2 P=0.139 \\
3 P=0.829\end{array}$ & $\begin{array}{l}1 P=0.110 \\
2 P=0.415 \\
3 P=0.586\end{array}$ & $\begin{array}{l}1 \mathrm{P}=0.588 ; \\
2 \mathrm{P}=0.130 ; \\
3 \mathrm{P}=0.732\end{array}$ \\
\hline $\begin{array}{l}\mathrm{G} 10(\mathrm{STZ}+ \\
\text { metformin } 150 \mathrm{mg})\end{array}$ & $42.81 \pm 1.52$ & $4.07 \pm 0.10$ & $1.12 \pm 0.08$ & $1.05 \pm 0.16$ & $1.02 \pm 0.21$ \\
\hline Significance & $\begin{array}{l}1 \mathrm{P}=0.426 \\
2 \mathrm{P}=0.153 \\
3 \mathrm{P}=0.199 \\
4 \mathrm{P}=0.484\end{array}$ & $\begin{array}{l}1 \mathrm{P}=0.001 ; \\
2 \mathrm{P}=0.001 ; \\
3 \mathrm{P}=0.001 ; \\
4 \mathrm{P}=0.412\end{array}$ & $\begin{array}{l}1 P=0.506 \\
2 P=0.108 \\
3 P=0.937 \\
4 P=0.891\end{array}$ & $\begin{array}{l}1 P=0.110 \\
2 P=0.415 \\
3 P=0.586 \\
4 P=1.000\end{array}$ & $\begin{array}{l}1 \mathrm{P}=0.941 ; \\
2 \mathrm{P}=0.234 ; \\
3 \mathrm{P}=0.496 ; \\
4 \mathrm{P}=0.732\end{array}$ \\
\hline
\end{tabular}

Data are expressed as mean +/- standard error. 1P: significance versus G6; 2P: significance versus G7; 3P: significance versus G8; 4P: significance versus G9; using OneWay ANOVA test (LSD). 
were taken and cultured in Trypticase soy agar media (TSA), then incubated at $27^{\circ} \mathrm{C}$ for $72 \mathrm{hrs}$.

\section{Histological Examination}

Decalcification was done in $10 \%$ nitric acid $\left(\mathrm{HNO}_{3}\right)$ and $10 \%$ formic acid $\left(\mathrm{HCO}_{2} \mathrm{H}\right)$ changes.

Following paraplast embedding, thick longitudinal sections of proximal 4 micron\& distal long bone ends were cut with a rotary microtome.

The histological examination was done according to standard protocol.

Haemotoxylin and Eosin staining was performed. The results were analyzed statistically for evaluation of the significance.

Analysis of bone morphology, considered length, cross-sectional area, thickness, weight, volume, and density, were done according to Ahmad et al. ${ }^{35}$.

\section{RESULTS}

\section{Statistical Analysis}

Table (1) showed the bone parameters in different groups along the experiment days. Bone length was significantly increased in $\mathrm{G} 7$ (Zingiber officinale) and G8 (Nigella Sativa) versus G6 (diabetic control) but was significantly decreased in G9 (Punica granatum) versus G7. Bone thickness was significantly increased in G7, G8, G9 and G10 (Metformin) versus G6 and increased in G9 and $\mathrm{G} 10$ versus $\mathrm{G} 7$ and $\mathrm{G} 8$. Bone volume was significantly increased in $\mathrm{G} 8$ versus $\mathrm{G} 6$.

Comparison of all bone length, thickness, weight, volume, anddensityin different studied groups, are shown in Figures 1, 2, 3, 4 and 5.

\section{Histopathology of Bone}

All the Decalcified bone tissue of study groups shows normal lamellar bone morphology arranged in regular parallel arrays. Osteocytes are seen within small lacunae having a dark nucleus with normal appearance Figures (6), (7), (8), (9), and (10).

\section{Culture Observation}

After bone swab culture, no bacterial growth was observed in all the studied groups.

\section{DISCUSSION}

The different substances studied in this study have been well documented for their wide variety of actions. Metformin reduces insulin resistance have been known to possess more than one mechanism of action. Ginger and Nigella Sativa also are known to possess various therapeutic effects, including a reduction in serum glucose, anti-inflammatory, antioxidant and antimicrobial, etc. In previous studies, these substances have been found effective in preventing diabetes induced complication, preventing the cell damage. Punica granatum have also been studied and is known to be rich in antioxidants which reduce oxidative stress. Reduction in oxidative stress is directly proportional to reduction in free radical formation and the prevention of cellular damage $8,24,36,37$.

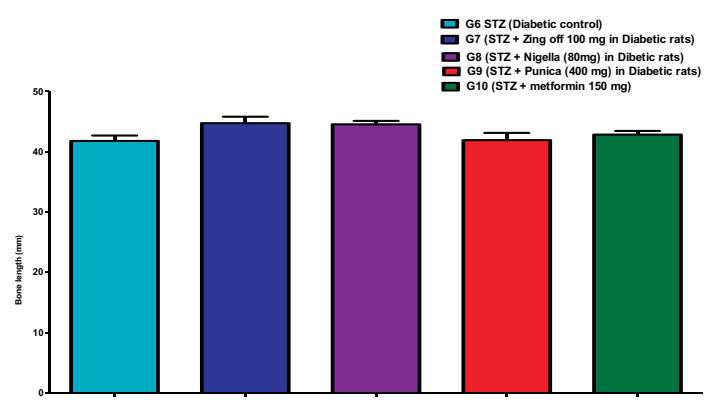

Fig. 1. Comparison of the bone length $(\mathrm{mm})$ in different studied groups.

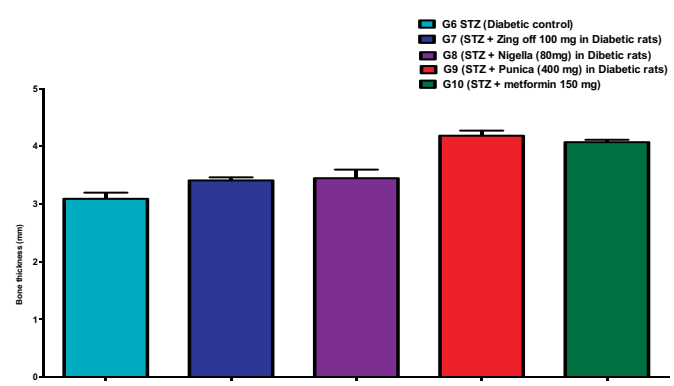

Fig. 2. Comparison of the bone thickness $(\mathrm{mm})$ in different studied groups.

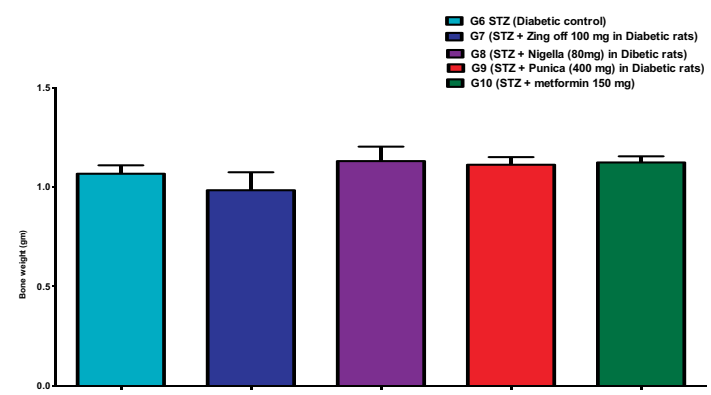

Fig. 3. Comparison of the bone weight (gram) in different studied groups. 


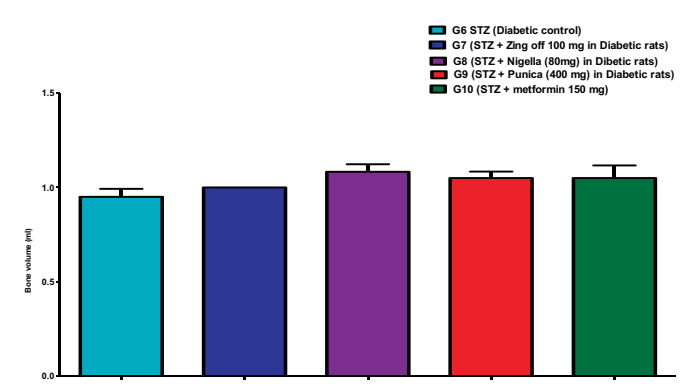

Fig. 4. Comparison of the bone volume $(\mathrm{ml})$ in different studied groups.

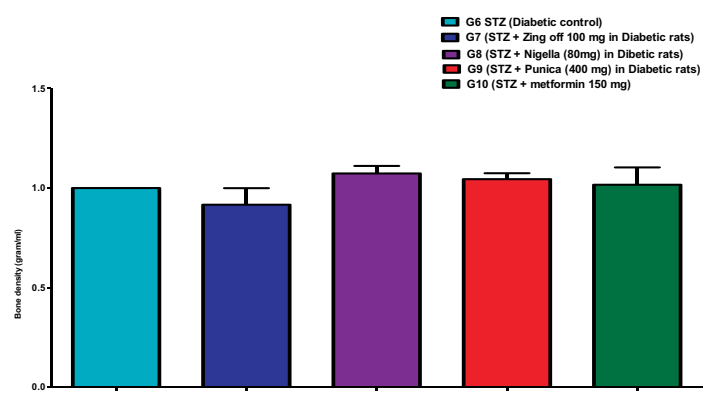

Fig. 5. Comparison of the bone density $(\mathrm{gram} / \mathrm{ml})$ in different studied groups.

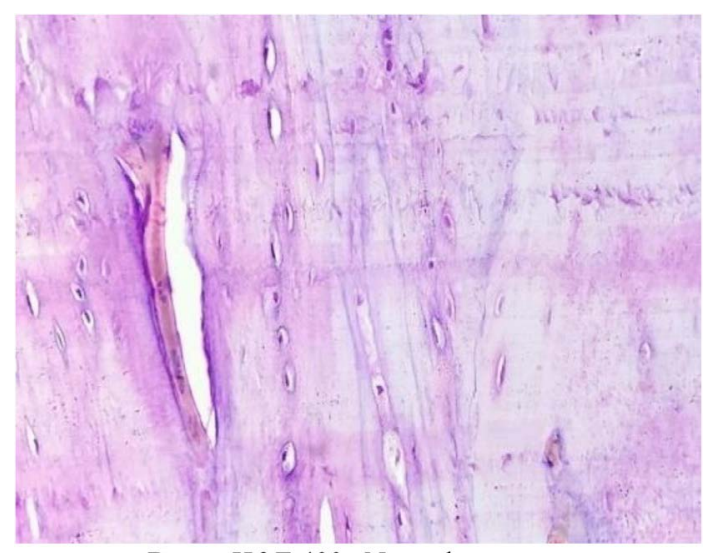

Bone - H\&E 400x Normal structure.

Fig. 6. Histopathology of decalcified bone of group 6 (Diabetic control).

In the present study, no bacterial growth was seen in the bones, in all the studied groups, at the same time in Metformin, Ginger, and Nigella sativa groups, a significant increase was found in bone length, volume and thickness.

All the substances studied, also have shown significant reduction in hyperglycemia.

In comparison to previous studies, the results of our study regarding Metformin

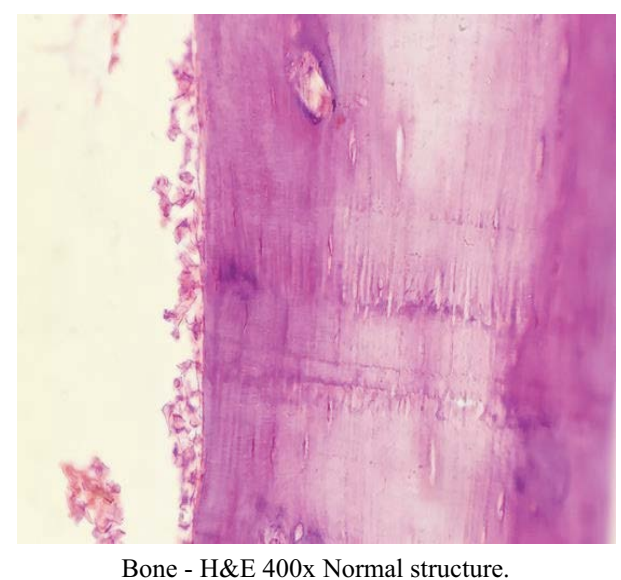

Fig. 7. Histopathology of decalcified bone of group 7 (Ginger in diab.Group).

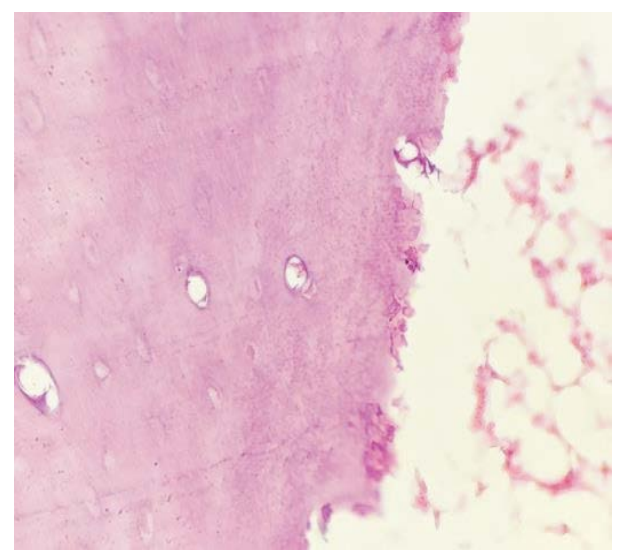

Bone - H\&E 400x Normal structure.

Fig. 8. Histopathology of decalcified bone of group 8 (Nigella in diab.Group).

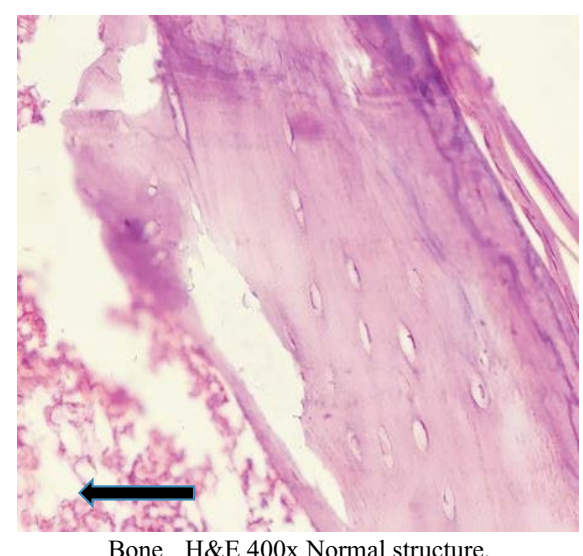

Fig. 9. Histopathology of decalcified bone of group 9 (Punica in Diab.). 


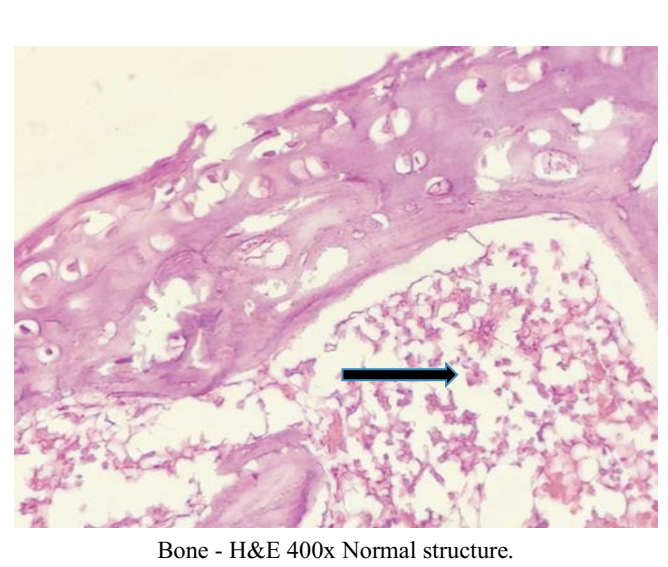

Fig. 10. Histopathology of decalcified bone of group 10 (Metformin in Diab. group).

protective effect on diabetes induced bone degradation, tally with the study conducted by ${ }^{38}$. As Metformin reduced blood glucose levels, which behave as good culture media for bacterial growth, reductions that medium resulted in no growth of microorganisms which is a common phenomena seen in diabetes, indirectly reducing the risk for infections.

Streptozotocin-induced diabetic animals also show many of the complications seen inhuman diabetic patients, including enhanced susceptibility to infection and cardiovascular disease, retinopathy, changes in angiogenesis, delayed wound healing, diminished growth factor expression, and reduced bone synthesis ${ }^{39,40}$.

The relationship between diabetes and osteoporosis is complex.

These days osteoporosis is considered as a main outcome of Diabetes mellitus. DM can affect bone via several mechanisms like insulin deficiency, insulin resistance, hyperglycemia and atherosclerosis. However, the exact cause that is responsible for osteopenia in DM is yet to be known ${ }^{41}$. Insulin and insulin-like growth factors (IGF-1) may have some function to play in the pathogenesis of diabetic-induced bone loss due to their anabolic effects ${ }^{42}$.

The results of this study regarding Nigella Sativa, preventing the bone degradation are in conformity with the previous studies ${ }^{43,44}$. The current study results show that Nigella Sativa also increased the bone mass, strength, matrix, volume and length. This can be attributed to its being rich in antioxidants thereby causing a decrease in oxidative stress. Regarding prevention of infection in this study, it is well documented for the Nigella Sativa that it contains anti-bacterial, anti-viral and antifungal effects ${ }^{45,46,47}$.

In present study, Ginger i.e. Zingiber officinale, also was found to protect the bone from Diabetes induced damage and it has not merely protected the bone from damage and infections, but also increased the bone mass, density, volume and strength as well ${ }^{48}$.

Antibacterial effects of Ginger are well known, therefore, the prevention of infections can be attributed to this effect while having anti-inflammatory, anti-oxidant effects can hold responsible for increase in bone mass, volume, density and strength ${ }^{49}$. Results of our study are matching with the previously conducted studies ${ }^{50}$.

In current study, Punica granatum (Pomegranate) was also observed to prevent the Diabetes induced bone damage at the same time it also caused increases in Bone mass, density, volume and strength. All of these effects pertain to pomegranates being rich in antioxidants and the consequent prevention of free radical formation and reduction in oxidative stress. These results are found similar to the previous studies ${ }^{4,52}$.

\section{CONCLUSION}

Diabetes mellitus is notorious to cause complications in all the systems, including musculoskeletal system, leading to early occurrence of osteoporosis. Hyperglycemia due to decrease or dysfunctional Insulin works as a medium for bacterial growth. Osteomyelitis, an infection of bone is very difficult to treat. The best approach to counter the DM related complications is to prevent these.

The substances used in this study, directly (Nigella sativa and Ginger has anti-hyper glycemic effects and antibacterial activity) and indirectly (Punica granatum and Metformin causes decrease in blood glucose levels), prevented the infections.

At the same time all the studied groups having effects on oxidative stress (Punicagranatum and Metformin) and possessing antiinflammatory effects as well (Nigella sativa and Ginger), not merely prevented the bone damage but also caused increases in bone volume, strength, matrix, length and density. 
It is suggested that further investigations should be conducted for verification of the results of this study with different methodology and longer duration of study. However it is recommended that these substances should be considered as adjuvant therapy in the treatment of Diabetes mellitus and prevention of DM related infections and bone damage.

\section{ACKNOWLEDGEMENTS}

None.

\section{CONFLICT OF INTEREST}

The author declares that there are no conflict of interest.

\section{REFERENCES}

1. Moseley K F. Type 2 diabetes and bone fractures. Curr Opin Endocrinol Diabetes Obes, 2012; 19 (2): 128-135.

2. Gong Z, Muzumdar RH. Pancreatic function, type 2 diabetes, and metabolism in aging. International Journal of Endocrinology, vol. 2012, Article ID 320482, 13 pages, 2012.

3. Yan W, Li X. Impact of diabetes and its treatments on skeletal diseases. Frontiers of medicine, 2013; 7(1): 81-90.

4. Yamagishi S. Role of advanced glycation end products (AGEs) in osteoporosis in diabetes. Curr Drug Targets, 2011; 12(14): 2096-2102.

5. Pacios S, Andriankaja O, Kang J, et al. Bacterial infection increases periodontal bone loss in diabetic rats through enhanced apoptosis. Am J Pathol, 2013; 183(6): 1928-19355.

6. Baynes JW, Thorpe SR. Role of oxidative stress in diabetic complications: a new perspective on an old paradigm. Diabetes, 1999; 48(1): 1-9.

7. Sangi S M, Sulaiman M I, El-wahab M F, Ahmedani E I, Ali S S.Antihyperglycemic effect of thymo-quinone and oleuropein, on streptozotocin induced diabetes mellitus in experimental animals. Phcog Mag, 2015; 11(25): 1-7.

8. Lecka-Czernik B. Safety of anti-diabetic therapies on bone. Clin Rev Bone Miner Metab, 2013 ; 11: 49-58.

9. Zhou G, Myers R, Li Y, Chen Y, Shen X, Fenyk-Melody J, et al. Role of AMP-activated protein kinase in mechanism of metformin action. J Clin Invest, 2001; 108(8): 11671174

10. Vestergaard P, Rejnmark L, Mosekilde L. Relative fracture risk in patients with diabetes mellitus, and the impact of insulin and oral antidiabetic medication on relative fracture risk. Dia-betologia, 2005; 48(7): 1292-9.

11. Gao Y, Xue J, Li X, Jia Y, Hu J. Metformin regulates osteoblast and adipocyte differentiation of rat mesenchymal stem cells. J Pharm Pharmacol, 2008; 60(12): 1695-700.

12. Shah $M$, Kola $B$, Bataveljic A, Arnett TR, Viollet $B$, Saxon $L$, et al. AMP-activated protein kinase (AMPK) activation regulates in vitro bone formation and bone mass. Bone,2010; 47(2): 309-19.

13. Gao Y, Li Y, Xue J, Jia Y, Hu J. Effect of the anti-diabetic drug metformin on bone mass in ovariectomized rats. Eur J Pharmacol,2010; 635(1-3):231-6.

14. Mai Q G, Zhang Z M, Xu S, Lu M, Zhou R P, Zhao L, et al. Metformin stimulates osteoprotegerin and reduces RANKL expression in osteoblasts and ovariectomized rats. Journal of cellular biochemistry, 2011; 112(10): 2902-9.

15. Zinman B, Haffner SM, Herman WH, Holman RR, Lachin JM, Kravitz BG, et al. Effect of rosiglitazone,metformin, and glyburide on bone biomarkers in patients with type 2 diabetes. The Journal of clinical endocrinology and metabolism, 2010; 95(1): 134-42.

16. Kirui P K, Cameron J, Benghuzzi H A, Tucci M, Patel $R$, Adah $F$, et al., Effects of sustained delivery of thymoqiunone on bone healing of male rats, Biomed Scilnstrum, 2004; 40: 111-116.

17. Ozdemir H, Kara M I, Erciyas K, Ozer H,Ay S. Preventive effects of thymoquinone in a rat periodontitis model: a morphometric and histopathological study. J Periodontal Res, 2012; 47: 74-80.

18. Kara M I, Erciyas K, Altan A B, Ozkut M, Ay S, Inan S. Thymoquinone accelerates new bone formation in the rapid maxillary expansion procedure, Arch Oral Biol, 2012; 57: 357-363.

19. Geerlings SE, Hoepelman Al. Immune dysfunction in patients with diabetes mellitus (DM). FEMS Immunol Med Microbiol, 1999; 26: 256-65.

20. Muller LM, Gorter KJ, Hak E, Goudzwaard WL, Schellevis FG,Hoepelman Al, et al. Increased risk of common infections in patients with type 1 and type 2 diabetes mellitus. Clin Infect Dis 2005; 41: 281-288.

21. Kiuchi F, Iwakami S, Shibuya M, Hanaoka F, Sankawa $U$. Inhibition of prostaglandin and leukotriene biosynthesis by gingerols and diarylheptanoids. Chem Pharm Bull (Tokyo),1992; 40(2): 387-91.

22. Vardakas KZ, Siempos II, Falagas ME. Diabetes mellitus as a riskfactor for nosocomial pneumonia and associated mortality. Diabet Med, 2007; 24: 11681171.

23. Zhang XF, Tan BK. Effects of an ethanolic extract of Gynuraprocumbens on serum glucose, chole-sterol and triglyceride levels in normal and streptozotocininduced diabetic rats. Singapore Med J., 2000; 41(1): 9-13.

24. Sangi, S. A., Bawadekji, A., Ali, M. A. Comparative effects of metformin, Pleurotus ostreatus, Nigella Sativa, and Zingiberofficinale on the strepto-zotocininduced diabetes mellitus in rats. Pharmacognosy Magazine, 2018;14(55): 268.

25. Al-Said FA, Opara LU, Al-Yahyai RA. Physical, chemical andtextural quality attributes of pomegranate cultivars (PunicagranatumL.) cultivars in Eastern Mediterranean region of Turkey. Afr. J. Biotechnol., 2009; 7: 12941301.

26. Akbarpour V, Hemmati K, Sharifani M. Physical and chemicalproperties of pomegranate, fruit in maturation stage. Am Eurasian J. Agric. Environ. Sci., 2009; 6: 411-416.

27. Shaygannia E, Bahmani M,Zamanzad Z, Rafieian-Kopaei 
M. A Review Study on Punicagranatum L. Journal of Evidence-Based Complementary \& Alternative Medicine, 2016; 21(3): 221-227

28. Pham-Huy LA, He H, Pham-Huy C. Free radicals, antioxidants in disease and health. IJBS, 2008; 4(2): 89-96.

29. Rahimi R, Nikfar S, Larijani B, Abdollahi M. Areview on the role of antioxidants in the management of diabetes and its complications. Biomedicine and Pharmacotherapy, 2005; 59(7): 365-373.

30. VincentA M, Russell J W, Low P, Feldman E L. Oxidative stress in the pathogenesis of diabetic neuropathy. Endocrine Reviews, 2004; 25(4): 612-628,

31. PariL, Latha M. Antidiabetic effect of Scopariadulcis: effect on lipid peroxidation in streptozotocin diabetes. General Physiology and Biophysics, 2005; 24(1): 13-26.

32. Droge W.Free radicals in the physiological control of cell function. Physiol Rev, 2011; 82: 47-95.

33. Freidovichl. Fundamental aspects of reactive oxygen species, or what's the matter with oxygen?.Ann NY AcadSci, 1999; 893: 13-18.

34. WeselerA R, Bast A. Oxidative stress and vascular function: implications for pharmacologic treat-ments. Curr Hypertension Rep, 2010; 12(3): 154-161.

35. Ahmad T.Skeletal changes in type-2 diabetic GotoKakizaki rats. Journal of Endocrinology,2003; 178 (1): 111-116.

36. Qaseem A, Humphrey LL, Sweet DE, Starkey M, ShekelleP. Oral pharmacologic treatment of type 2 diabetes mellitus: a clinical practice guideline from the American College of Physicians. Annals of Internal Medicine, 2012; 156(3): 218-231.

37. Middha S K, Usha T, Pande V. A Review on Antihyperglycemic and Antihepatoprotective Activity of Eco-Friendly Punicagranatum Peel Waste. EvidenceBased Complementary and Alternative Medicine, 2013; 2013: 10 pages, Article ID 656172.

38. LiX, Guo Y, Yan W, Snyder M P, Li X. Metformin Improves Diabetic Bone Health by Re-Balancing Catabolism and Nitrogen Disposal. Plos One, 2015; 10(12): e0146152.

39. Mosci P, Vecchiarelli A, Cenci E, Puliti M, Bistoni F. Low dose streptozotocin-induced diabetes in mice. Cell Immunol, 1993; 150: 7-35.

40. Kunjathoor V, Wilson D, LeBoeuf R. Increased atherosclerosis in streptozotocin-induced diabetic mice. J Clin Invest, 1996; 97: 1767-1773.

41. Okazaki R. Diabetes mellitus and bone metabolism.
Clinical Calcium, 2011; 21(5): 669-675.

42. Pater A, and Odrowa G. Alterations of bone metabolism in children and adolescents with diabetes mellitus type 1.The Pediatric Endocrinology Diabetes and Metabolism, 2011; 17(3): 158-161.

43. Kirui P K, Cameron J, Benghuzzi H A, Tucci M, Patel $\mathrm{R}$, Adah $\mathrm{F}$, et al. Effectsof sustained delivery of thymoqiunone on bone healing of male rats. Biomed Scilnstrum, 2004; 40: 111-116.

44. H. Ozdemir, M.I. Kara, K. Erciyas, H. Ozer, S. Ay, Preventive effectsofthymoquinone in a rat periodontitis model: a morphometric and histopathological study, J Periodontal Res, 2012; 47: 74-80.

45. Ugur AR, Dagi H T, Ozturk B, Tekin G, Findik D. Assessment of In vitro Antibacterial Activity and Cytotoxicity Effect of Nigella sativa oil. Pharmacogn Mag, 2016; 12(4): 71-74.

46. Shokri H. A review on the inhibitory potential of Nigella sativa against pathogenic and toxigenic fungi. Avicenna J Phytomed, 2016; 6(1): 21-33.

47. Barakat EMF, El Wakeel LM, Hagag R S. Effects of Nigella sativa on outcome of hepatitis C in Egypt. World J Gastroenterol,2013; 19(16):2529 -2536.

48. Ippoushi K, Azuma K, Ito H, Horie H, Higashio H. Gingerolinhi bitsnitricoxidesyn the sisin activated J774.1mouse macrophages and prevents peroxynitrite induced oxidation and nitration reactions. Life Science, 2003; 73(26): 3427-3437.

49. El-Sharaky AS, Newairy AA, Kamel MA, Eweda SM. Protective effect of ginger extract against bromobenzene-induced hepatotoxicity in male rats. Food ChemToxicol, 2009; 47: 1584-90.

50. Kamrul Islam, Asma Afroz Rowsni, Md. Murad Khan, Md. ShahidulKabir. Antimicrobial Activity Of Ginger (Zingiberofficinale) Extracts Against Food-Borne Pathogenic Bacteria. International Journal of Science, Environment and Technology, 2014; 3(3): 867-871.

51. Mansour S W, SangiS, Harsha S, Khaleel M A, Ibrahim A R. Sensibility of male rats fertility against olive oil, Nigella sativa oil and pomegranate extract. Asian Pacific journal of tropical biomedicine, 2013; 3 (7): 563-568.

52. Shiban M S, Al-Otaibi M M, Al-Zoreky N S. Antioxidant Activity of Pomegranate (Punica-granatum L.) Fruit Peels. Food and Nutrition Sciences, 2012; 03(07): 991996. 